\title{
Financial Crisis and the Optimization of Undergraduates' Concept of Job-choosing
}

\author{
Chenglong Pan \\ Zhejiang Gongshang University, Hangzhou Business School, Taizhou, Zhejiang, China \\ zhiyatai727@163.com \\ Chenglong Pan
}

Keywords: Financial crisis, college students, career choice, optimization.

\begin{abstract}
Since the outbreak of the financial crisis in 2008, China's economy has also suffered major impacts, and the employment situation of Chinese college students has also suffered major blows. The difficulty in obtaining employment for university students has become a common phenomenon. Under such circumstances, which choice should college graduates make to increase the probability of employment? This paper starts from the current social requirements for college students, and we discussing the employment situation and employment prospects of college graduates after the financial crisis by studying the psychology of employment and the concept of job hunting. In view of the problem of undergraduate employment under the economic downturn, we put forward certain opinions and suggestions to optimize the concept of college students' career selection in order to increase the employment rate of university graduates.
\end{abstract}

\section{金融危机与大学生择业观念的优化 \\ 潘成龙 \\ 浙江工商大学杭州商学院, 台州, 浙江, 中国 zhiyatai727@163.com}

潘成龙

关键词: 金融危机; 大学生; 择业; 优化

摘要.自 2008 年金融危机爆发以来, 我国经济也受到重大冲击, 我国大学生的就业形势也遭 遇重大打击, 大学生就业难现象已经成为普遍现象。在这种情况下, 大学生应当作何选择来 提高就业的概率? 本文通过对目前社会对大学生的要求出发, 通过研究大学生就业的心理与 择业观念, 探讨金融危机后大学毕业生所应对的就业形势与就业前景。针对经济不景气下的 大学生就业问题, 提出一定的意见与建议, 优化大学生的择业观念, 以期提高大学毕业生的 就业率。

\section{1.引言}

在如今全球化进程如此大覆盖面的情况下, 金融危机对我国实体经济以及金融的影响十 分严重, 这也就导致了经济增长放缓, 使得就业形势更加严峻。且随着大学扩招的进行, 每 年的大学毕业生都在逐步增加, 就业岗位的减少, 毕业生的增加, 这使得就业与毕业生之间 供求关系极度不平衡。这也就给大学生就业提出了严峻的考验。

但目前社会对大学毕业生的评价并不高, 大学毕业生想要在严峻的就业环境下实现自己 的理想, 必须优化自身的就业理念以及择业思想。而优化大学毕业生的就业理念与择业思想 
必须要有足够的信息服务, 使得大学生明白自己的定位以及平稳学生的情绪。

新中国成立以来，我国经济、文化等方面发生了极大的变化，人们的物质条件都得到了 较大满足, 使得当代大学生的思想观念发生了较大变化。大学生中也不乏个人主义、拜金主 义的积极拥护者, 这也为大学生的就业造成了极大的影响。

\section{2.大学生择业观念现状}

在这个互联网发达的年代, 大学生都能从网络上获取较多的就业信息以及了解目前的就 业形势。但网络上的消息不够全面以及系统, 大学生只能在网上了解只言片语, 这也就使得 大学生对当前就业形势以及就业现状并不了解。在大部分大学中, 学生只有在最后一年内才 会了解到招聘会以及就业信息, 这也就使得学生对当前的就业形势并不能有一个良好的判断。

学校的就业指导中心对大学生有着极为重要的指导作用, 能够使得学生了解最近几年的 就业状况以及对今后的就业形势做出一个正确的判断。针对面前大学生就业观念的现状研究, 对附近几所大学的学生进行了一个简单的问卷调查。调查问卷有两个问题: 1. 你认为哪些因 素会导致你就业失败（多选）？；2. 你对自己的职业生涯有进行规划吗？共发放问卷 300 份, 回收 280 份，回收率为 93.3\%。一下为问卷调查的结果分析。

表 1 导致就业失败的因素

\begin{tabular}{|c|c|c|c|c|}
\hline & $\begin{array}{l}\text { 就业信息较 } \\
\text { 少 }\end{array}$ & $\begin{array}{c}\text { 公司不愿招收应届 } \\
\text { 毕业生 }\end{array}$ & 大学生就业能力不足 & 大学生自身定位不准 \\
\hline 人数 & 135 & 107 & 203 & 69 \\
\hline 占比 (\%) & 48.2 & 38.2 & 72.5 & 24.6 \\
\hline
\end{tabular}

从调查结果我们可以看出, 认为导致就业失败的因素中大学生就业能力不足占比最高, 72.5\%的学生认为大学生就业能力不足是导致大学生就业失败的因素之一。而就业信息较少占 比 $48.2 \%$, 公司不愿招收应届毕业生占比 $38.2 \%$, 而大学生自身定位不准占比达 $24.6 \%$ 。从学 生的角度而言, 就业能力不足以及就业信息的不到位是导致就业难的主要因素。从调查结果 来看, 大学生对自身存在的问题的了解还是较为全面。面对这种情况, 学校的就业指导中心 应当及时对大学生就业信息进行更新以及大学应当着重培养学生的工作能力以及学习能力。

下图为你对自己的职业生涯有进行规划的调查结果:

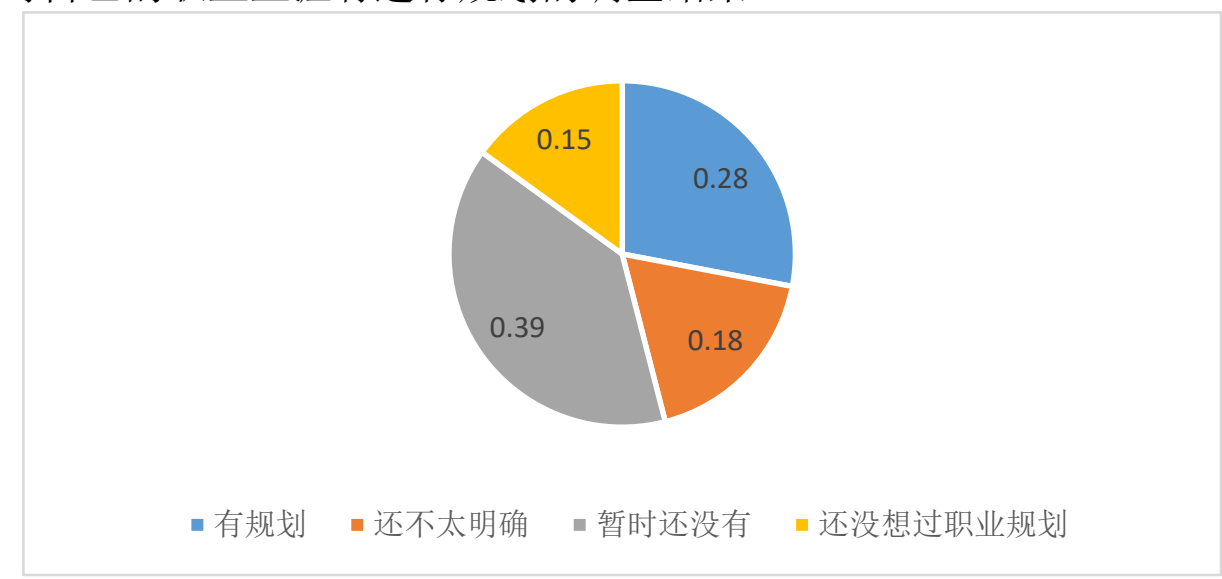

图 1 对自身职业生涯有无规划

从表中我们可以看出占比最大的为暂时还没有对自己的职业生涯进行规划的大学生，这 说明大学生对自身职业生涯并没有一个很好的认识, 学校也并没有在这些方面对学生进行引 导。

综上所述, 目前大学生普遍认为自己就业能力不足，且不能接收到全面的就业信息。但 大学生对自己的职业生涯认识不足, 对未来也较为迷茫。 


\section{3. 大学生就业观念的优化}

\section{1 大学生应当认识到自身的定位}

在当代社会, 社会对大学生的要求已经不仅仅局限于读书成绩好, 同时也要求学生应当 全面发展。在这些方面, 大学生应当在大学期间, 积极参加集体活动来增加自己的组织能力 以及语言表达能力, 努力增强自身的工作能力。

大学生应当充分认识到自身的定位, 对薪资的要求应当恰当, 及时把握住较为不错的就 业机会。大学生不应当因为就业形势严峻而妄自菲薄, 也不能对自己自视甚高。应当清楚地 认识到自身的定位, 把握住机会。

\section{2 大学生应当积极关注就业信息并把握就业机会}

现在的社会是一个信息的社会，只有积极关注就业信息，才能实现大浪淘沙，在众多工 作中寻找到适合自己的职业。同时, 目前的就业较为严峻, 大学生应当紧密关注就业信息, 不错过任何一个就业的机会。

虽然金融危机对我国经济有较大冲击, 但我国是一个庞大的经济体，且经济仍然处于上 升阶段, 我国企业对于应届毕业生的需求仍然较大。在这种情况下, 大学生应当注意各公司 的招聘信息以及招聘会信息，对各类招聘会积极参与。广大的大学毕业生应当积极地调整好 自己的心态，积极地关注各类就业信息，同时把握每一个就业机会。

\section{3 大学生应当不惧失败}

各类招聘会较多，但竞争也较大，大学生在参与招聘的过程中难免不会遭遇到失败。可 能由于性别限制, 可能由于工作能力, 也有可能是因为面试表现不佳导致了应聘的失败。但 失败也并不意味着失去了机会。大学生应当吸取每一次失败的经验教训, 在不断的学习中充 实自己，使得自己逐步满足招聘单位的招聘要求。

面试其实也是一个学习的过程, 在面试中, 通过面试官的问题, 我们可以较为深刻地意 识到自身可能存在的各种问题。只有在面试后进行总结，才会在下一次的应聘中发挥出色。 大学生应当不畏惧应聘中的失败, 在失败中汲取教训与经验, 不断丰富自己, 才能使自己成 为优秀的人。

\section{4 学校应当对学生集中进行就业指导}

目前的大学现状是大部分大学生到了毕业季才开始关注就业信息以及开始制作简历以及 思考未来的发展方向。学校应当在大二就给学生灌输就业的观念, 并且及时地根据不同学生 进行就业信息的调整。并且让同学了解到学长学姐的就业情况以及该专业的就业方向。

就业指导不仅能够指导学生对以后的学习生活进行规划, 同时, 就业指导也能够帮助学 生树立自己的目标，并不断向着目标前进。同时，学校应当举行就业信息讲座，请公司招聘 负责人以及学生代表讲授公司所需要的人才所应当具备的能力, 同时传授给学生在招聘是应 当注意的事项已经应答技巧。

\section{4. 结束语}

金融危机对经济的冲击使得就业形势更加严峻，但在这份严峻的就业形势中，学生应当 及时转换自己的思想, 将自己放在一个恰当的定位上。同时大学生应当不断丰富自己的社会 经历以及增强自己的工作能力，使得自己能在招聘时得到公司的认可。

就业信息对大学生来说也是极为重要的, 学生应当积极关注就业信息以及关注就业动态, 为自己的应聘做好充分的工作。同时, 学校应当对学生进行就业指导, 使得学生明白就业的 严峻, 同时也让学生不要失去就业的信心。学校应当对学生的简历制作以及面试技巧进行培 训, 增强学生的应变能力。 


\section{References}

[1] Xi. Education Economics [M]. People's Education Press, 2008.

[2] Lu. The theoretical thinking triggered by the financial crisis [J]. Contemporary Economy, 2008.

[3] Zhu. British University Student Employment Ability Training Model and Its Enlightenment [J]. World Education Information, 2010.

[4] Shi. Analysis of the impact of the global financial crisis on the employment of graduates of the Shanghai economics [D]. East China Normal University, 2010.

[5] Wang. An Analysis of College Students' Patriotic Psychology and Behavior in the Post-financial Crisis [J]. China Education Innovation Guide,2008.

[6] Tang. On the employment of college students in the context of the world financial crisis [J]. 2009, (01). 